\title{
Analisis Postur Kerja Operator Perakitan Di Yessy Shoes Untuk Mengidentifikasi Resiko Gangguan Muskuloskeletal Akibat Kerja
}

\author{
Ifen Alfara ${ }^{* 1)}$, Irwan Iftadi $^{2)}$, dan Rahmaniah Dwi Astuti ${ }^{2)}$ \\ ${ }^{1)}$ Mahasiswa Program Studi Teknik Industri, Universitas Sebelas Maret, \\ Jl. Ir. Sutami 36A, Surakarta 57126, Indonesia \\ ${ }^{2)}$ Laboratorium Perancangan Sistem Kerja Dan Ergonomi, Program Studi Teknik Industri, Universitas \\ Sebelas Maret, Jl. Ir. Sutami 36A, Surakarta 57126, Indonesia
}

\begin{abstract}
The application of ergonomics in work place is important because the lack of attention can cause health problems to worker, this can be performed by postural assessment using method of visual management, which assessing each elementary operation of a process to the selected domain ergonomics to produce PES (partial ergonomic score) and with a formula then value of OES (overall ergonomic score) is obtaned that shows the operation status of a process. The results obtained from this study is 5 process have value of OES in the range $0.4<O E S \leq 0.5$ so operation status is "investigate; change may be needed" while 17 process have value of OES in the range $0.5<O E S \leq 0.7$ so operation status is "investigate; change soon". The conclusion of this study is the change of work posture of the worker is needed, which can be conducted by designing a facility based on the elementary operation with the highest value of PES.
\end{abstract}

Keywords: postural assessment. visual management. musculoskeletal disorder

\section{Pendahuluan}

Postur kerja merupakan pengaturan sikap tubuh saat bekerja (Bridger, 1995). Postur kerja yang tidak alamiah tersebut dapat memicu terjadinya keluhan rasa nyeri seperti gangguan muskuloskeletal (musculoskeletal disorders, MSDs) (Budiman dan Setyaningrum, 2012). Gangguan muskuloskeletal adalah sekumpulan gejala yang berkaitan dengan jaringan otot, tendon, ligament, kartilago, sistem saraf, struktur tulang, dan pembulu darah (Tarwaka, 2004). Munculnya keluhan muskuloskeletal dari yang paling ringan hingga yang berat akan menggangu konsentrasi dalam bekerja, menimbulkan kelelahan dan pada akhirnya akan menurunkan produktivitas kerja seseorang (Hagberg and Kuorinka, 1997). Penciptaan sistem kerja yang memperhatikan kaidah ergonomi sudah terbukti mampu memberikan manfaat, baik bagi pekerjanya secara langsung maupun bagi perusahaan. Sistem kerja tersebut dapat menurunkan keluhan akibat gangguan muskuloskeletal, kelelahan, beban kerja, dan risiko cedera yang dialami oleh pekerja. Selain itu, produktivitas dan pendapatan pekerja dapat ditingkatkan. yang pada akhirnya akan meningkatkan keuntungan perusahaan (Adiputra, 2006).

Yessy Shoes merupakan salah satu industri rumah tangga (home industry) yang kegiatan utamanya bergerak di bidang produksi sepatu. Cecchini et al., (2010) mengatakan bahwa beberapa kegiatan yang dilakukan dalam sistem perakitan, khususnya yang terkait dengan gerakan berulang-ulang dan dengan tingkat stres tertentu atau dengan asumsi lanjut yaitu postur tidak nyaman, sangat mungkin menyebabkan gangguan muskuloskeletal akibat kerja. Berdasarkan observasi lapangan, terdapat bagian di mana postur kerja pekerja stasiun perakitan dipandang kurang ergonomis karena pekerja melakukan postur kerja yang salah (awkward posture) dan postur kerja itu dilakukan berulang. Proses perakitan sepatu dilakukan dengan

\footnotetext{
*Correspondance : alfara.ifen@gmail.com
} 
menggunakan alat bantu berupa tiruan kaki berbahan kayu yang dinamakan sulas (laste). Setiap pekerja menyusun \pm 24 sulas di lantai perakitan, sehingga setiap kali membutuhkan sulas tersebut pekerja yang duduk di kursi harus membungkuk ke bawah atau menjangkau ke belakang untuk mengambilnya. Begitu pula setelah selesai melakukan perakitan, pekerja meletakkan kembali sulas ke tempatnya dengan postur kerja yang sama. Hal ini menunjukkan bahwa pekerjaan di stasiun perakitan sangat berpotensi menimbulkan gangguan muskuloskeletal karena selain melakukan postur kerja yang tidak alamiah, postur tersebut dilakukan secara berulang.

Hal ini diperkuat dengan hasil kuesioner Nordic Body Map (NBM), yaitu kuesioner yang dikembangkan oleh Kuorinka et al, (1987) dan Dickinson et al, (1992). Kuesioner diberikan kepada pekerja di semua stasiun kerja menunjukkan bahwa pekerja di stasiun perakitan merasakan keluhan rasa sakit bagian tubuh paling banyak. Pekerja perakitan mengeluhkan rasa sakit atau nyeri pada bagian-bagian tubuh seperti sakit/kaku di leher bagian atas, punggung, lengan atas kanan, pinggang, pantat dan sakit di pergelangan tangan kanan setelah bekerja.

Dari pengamatan tersebut terlihat bahwa pada stasiun perakitan terdapat permasalahan terkait postur kerja yang dilakukan. Penelitian ini bertujuan untuk menilai postur kerja pekerja stasiun perakitan di home industry Yessy Shoes dengan metode visual management.

\section{Metode Penelitian}

Penilaian postur kerja di stasiun perakitan Yessy Shoes dilakukan dengan menggunakan metode Visual Management. Seluruh aktivitas pekerja perakitan direkam sebagai bahan untuk melakukan penilaian ergonomi. Menurut Fagarasanu dan Kumar, (2002) menyatakan bahwa pengamatan kegiatan dengan kejadian diskret yang memiliki frekuensi tinggi, maka digunakan peralatan elektronik seperti kamera perekam untuk merekam kegiatan. Savino et al, (2016) mengatakan bahwa penilaian postur kerja dengan visual management dilakukan melalui 4 langkah yaitu pembagian ke dalam operasi dasar (elementary operation), penilaian ergonomi, evaluasi skor dan penilaian rekapitulasi ergonomi. Hasil akhir berupa keseluruhan skor ergonomi atau OES (Overall Ergonomic Scores). OES memiliki empat interval yang memberikan indikasi kekritisan postur kerja disertai dengan derajat kepentingan perbaikan sistem kerja. Analisis data dilakukan dengan menganalisis keluhan muskuloskeletal pada pekerja perakitan melalui postur kerja yang beresiko menyebabkan gangguan muskuloskeletal.

\section{Hasil dan Pembahasan}

Perakitan sepatu dilakukan secara manual dengan menggunakan perkakas tangan. Bagianbagian sepatu digabung menjadi satu dengan bantuan sulas (laste) melalui 22 proses yaitu, proses memola intek sebagai insole menggunakan mal, proses memotong intek menggunakan gunting, proses memilih sulas yang akan digunakan, proses merakit sulas dan intek dengan paku, proses mengoleskan lem ke ujung intek menggunakan kuas, proses merakit kain keras tipis ke ujung sulas intek, proses memotong kain keras tebal menggunakan gunting, proses menyesek kain keras tebal menggunakan pisau, proses merapikan cup/upper menggunakan gunting, proses mengoleskan lem ke intek menggunakan kuas, proses merakit cup/upper dengan kain keras tebal, proses merakit cup/upper dengan sulas intek, proses mengurai rakitan paku dari sulas intek, proses mengoleskan lem ke tamsin menggunakan kuas, proses merakit sulas intek dengan tamsin, proses memotong fiber menggunakan gunting, proses mengoleskan lem ke intek menggunakan kuas, proses merakit sulas intek dengan lembaran fiber, proses menghaluskan tepi cup/upper menggunakan amplas, proses mengoleskan lem ke tepi cup/upper menggunakan kuas, proses mengoleskan lem ke outsole menggunakan kuas dan proses merakit outsole dengan sulas intek. Dari hasil rekaman video, setiap operasi dari masing-masing proses 
diidentifikasi, sebagai contoh pada proses merakit sulas dan intek dengan paku terdiri dari 7 operasi dasar (EO) seperti yang terlihat dalam Tabel 1.

Tabel 1. Operasi Dasar Proses Merakit Sulas Dan Intek Dengan Paku

\begin{tabular}{cl}
\hline EO & \multicolumn{1}{c}{ Deskripsi Operasi } \\
\hline 1 & Menjangkau sulas y ang akan dirakit dari lantai stasiun perakitan \\
2 & Menjangkau intek di meja perakitan \\
3 & Mengarahkan intek ke tapak kaki sulas \\
4 & Menjangkau paku di meja perakitan \\
5 & Menjangkau dan memegang palu \\
6 & Menggunakan palu untuk memukul paku supaya intek dan sulas rekat \\
7 & Melepas sulas ke lantai stasiun perakitan \\
\hline
\end{tabular}

Tabel 2. Penilaian Postur Kerja Menjangkau Sulas Yang Akan Dirakit Dari Lantai Stasiun Perakitan

\begin{tabular}{rlccc}
\hline No & \multicolumn{1}{c}{ Domain Ergonomi } & Hasil Penelitian & $\begin{array}{c}\text { Level } \\
\text { Kekritisan }\end{array}$ & $\begin{array}{c}\text { Nilai } \\
\text { Kekritisan }\end{array}$ \\
\hline 1 & Sudut batang tubuh membungkuk & $31,56^{\circ}$ & Level 1 & 3 \\
2 & Ketinggian Lengan & lengan berada pada bahu & Level 2 & 2 \\
3 & Sudut lutut menekuk & $112,02^{\circ}$ & Level 1 & 3 \\
4 & Posisi beban y ang ditangani & meregangkan lengan & Level 2 & 2 \\
5 & Jumlah langkah berjalan & 0 & Level 3 & 1 \\
6 & Beban yang ditangani & 0,86 & Level 3 & 1 \\
7 & Sudut menekuk leher atau memutar & $26,18^{\circ}$ dan memutar & Level 1 & 3 \\
8 & Sudut memutar lengan bawah & $7,33^{\circ}$ & Level 3 & 1 \\
9 & Posisi kaki & duduk & Level 3 & 1 \\
10 & Sudut menekuk pergelangan tangan & $20,83^{\circ}$ & Level 1 & 3 \\
\hline \multicolumn{2}{c}{ Parsial Ergonomic Scores (PES) } \\
\hline
\end{tabular}

Visual management menilai postur kerja setiap operasi dasar terhadap 10 domain ergonomi yang dipilih sehingga menghasilkan nilai PES. Dengan mengacu pada warna yang digunakan untuk mewakili kekritisan ergonomi, tiga tingkat telah ditetapkan untuk masing-masing postur yang diidentifikasi, sebagai berikut: kekritisan rendah (level 3, warna hijau, nilai 1), kekritisan medium (level 2, warna kuning, nilai 2) dan kekritisan tinggi (level 3, warna merah, nilai 3). Tabel 2 menunjukkan penilaian postur kerja operasi dasar menjangkau sulas yang akan dirakit dari lantai stasiun perakitan terhadap 10 domain ergonomi yang dipilih.

Skor keseluruhan atau OES (overall ergonomic scores) dikaitkan dengan pekerja tersebut sesuai dengan evaluasi penilaian ergonomi. Prosedur ini memungkinkan kita untuk mendapatkan angka dari interval [0,1]. OES merangkum paparan ergonomi secara global dari pekerja. 
Tabel 3. OES Proses Merakit Sulas Dan Intek Dengan Paku

\begin{tabular}{llccccccc}
\hline \multirow{2}{*}{ No } & \multicolumn{1}{c}{ Domain Ergonomi } & \multicolumn{7}{c}{ Skor Kekritisan } \\
\cline { 3 - 8 } & & EO1 & EO2 & EO3 & EO4 & EO5 & EO6 & EO7 \\
\hline 1 & Sudut batang tubuh membungkuk & 3 & 2 & 1 & 2 & 2 & 2 & 2 \\
2 & Ketinggian Lengan & 2 & 1 & 1 & 1 & 1 & 1 & 1 \\
3 & Sudut lutut menekuk & 3 & 3 & 3 & 3 & 3 & 3 & 3 \\
4 & Posisi beban yang ditangani & 2 & 1 & 1 & 1 & 1 & 1 & 2 \\
5 & Jumlah langkah berjalan & 1 & 1 & 1 & 1 & 1 & 1 & 1 \\
6 & Beban yang ditangani & 1 & 1 & 1 & 1 & 1 & 1 & 1 \\
7 & Sudut menekuk leher atau memutar & 3 & 1 & 2 & 2 & 2 & 2 & 3 \\
8 & Sudut memutar lengan bawah & 1 & 1 & 1 & 1 & 1 & 1 & 1 \\
9 & Posisi kaki & 1 & 1 & 1 & 1 & 1 & 1 & 1 \\
10 & Sudut menekuk pergelangan tangan & 3 & 2 & 3 & 3 & 3 & 3 & 3 \\
\hline & Parsial Ergonomic Scores (PES) & 20 & 14 & 15 & 16 & 16 & 16 & 18 \\
\hline & Overall Ergonomic Scores (OES) & & & & 0,55 & & & \\
\hline
\end{tabular}

Tabel 3 menunjukkan kondisi masing-masing operasi dasar proses merakit sulas dan intek dengan paku EO1 terdiri dari 4 postur kerja dengan kekritisan tinggi (skor 3), 2 postur kerja dengan kekritisan medium (skor 2) dan 4 postur kerja dengan kekritisan rendah (skor 1). EO2 terdiri dari 1 postur kerja dengan kekritisan tinggi (skor 3), 2 postur kerja dengan kekritisan medium (skor 2) dan 7 postur kerja dengan kekritisan rendah (skor 1). EO3 terdiri dari 2 postur kerja dengan kekritisan tinggi (skor 3), 1 postur kerja dengan kekritisan medium (skor 2) dan 7 postur kerja dengan kekritisan rendah (skor 1). EO4, EO5 dan EO6 terdiri dari 2 postur kerja dengan kekritisan tinggi (skor 3), 2 postur kerja dengan kekritisan medium (skor 2) dan 6 postur kerja dengan kekritisan rendah (skor 1) sedangkan EO7 terdiri dari 3 postur kerja dengan kekritisan tinggi (skor 3), 2 postur kerja dengan kekritisan medium (skor 2) dan 5 postur kerja dengan kekritisan rendah (skor 1).

Tabel 3 menunjukkan pula nilai PES masing-masing operasi dasar untuk proses merakit sulas dan intek dengan paku yaitu PES EO1= 20, PES EO2=14, PES EO3= 15, PES EO4= 16, PES EO5= 16, PES EO6= 16, PES EO7= 18. Selanjutnya OES didapatkan dari perhitungan seperti berikut ini.

$$
\begin{aligned}
& \text { OES }=\frac{\sum_{i}^{j} \text { PES }}{3 \times \text { num.dom } \times \text { num.elem.ops }} \\
& \text { OES }=\frac{20+14+15+16+16+16+18}{3 \times 10 \times 7}=\frac{115}{210}=0,55
\end{aligned}
$$


Tabel 4. Nilai OES dan Status Operasi Di Stasiun Perakitan

\begin{tabular}{|c|c|c|c|}
\hline No & Proses Pada Stasiun Perakitan & OES & Status Operasi \\
\hline 1 & Memola intek sebagai insole menggunakan mal & 0,51 & Investigasi dan perubahan segera \\
\hline 2 & Memotong intek menggunakan gunting & 0,46 & $\begin{array}{l}\text { Diperlukan investigasi lebih lanjut, } \\
\text { perubahan mungkin diperlukan }\end{array}$ \\
\hline 3 & Memilih sulas y ang akan digunakan & 0,51 & Investigasi dan perubahan segera \\
\hline 4 & Merakit sulas dan intek dengan paku & 0,55 & Investigasi dan perubahan segera \\
\hline 5 & Mengoleskan lem ke ujung intek menggunakan kuas & 0,57 & Investigasi dan perubahan segera \\
\hline 6 & Merakit kain keras tipis ke ujung sulas intek & 0,52 & Investigasi dan perubahan segera \\
\hline 7 & Memotong kain keras tebal menggunakan gunting & 0,47 & $\begin{array}{l}\text { Diperlukan investigasi lebih lanjut, } \\
\text { perubahan mungkin diperlukan }\end{array}$ \\
\hline 8 & Menyesek kain keras tebal menggunakan pisau & 0,48 & $\begin{array}{l}\text { Diperlukan investigasi lebih lanjut, } \\
\text { perubahan mungkin diperlukan }\end{array}$ \\
\hline 9 & Merapikan cup/upper menggunakan gunting & 0,54 & Investigasi dan perubahan segera \\
\hline 10 & Mengoleskan lem ke intek menggunakan kuas & 0,57 & Investigasi dan perubahan segera \\
\hline 11 & Merakit cup/upper dengan kain keras tebal & 0,48 & $\begin{array}{l}\text { Diperlukan investigasi lebih lanjut, } \\
\text { perubahan mungkin diperlukan }\end{array}$ \\
\hline 12 & Merakit cup/upper dengan sulas intek & 0,56 & Investigasi dan perubahan segera \\
\hline 13 & Mengurai rakitan paku dari sulas intek & 0,57 & Investigasi dan perubahan segera \\
\hline 14 & Mengoleskan lem ke tamsin menggunakan kuas & 0,48 & $\begin{array}{l}\text { Diperlukan investigasi lebih lanjut, } \\
\text { perubahan mungkin diperlukan }\end{array}$ \\
\hline 15 & Merakit sulas intek dengan tamsin & 0,54 & Investigasi dan perubahan segera \\
\hline 16 & Memotong fiber menggunakan gunting & 0,54 & Investigasi dan perubahan segera \\
\hline 17 & Mengoleskan lem ke intek menggunakan kuas & 0,57 & Investigasi dan perubahan segera \\
\hline 18 & Merakit sulas intek dengan lembaran fiber & 0,54 & Investigasi dan perubahan segera \\
\hline 19 & Menghaluskan tepi cup/upper menggunakan amplas & 0,56 & Investigasi dan perubahan segera \\
\hline 20 & Mengoleskan lem ke tepi cup/upper menggunakan kuas & 0,57 & Investigasi dan perubahan segera \\
\hline 21 & Mengoleskan lem ke outsole menggunakan kuas & 0,55 & Investigasi dan perubahan segera \\
\hline 22 & Merakit outsole dengan sulas intek & 0,58 & Investigasi dan perubahan segera \\
\hline
\end{tabular}

Berdasarkan penilaian postur kerja dengan metode visual management, diperoleh nilai OES dan status operasi setiap proses di stasiun perakitan seperti yang ditunjukkan pada Tabel 4 . Terdapat 5 proses dengan nilai OES berada pada rentang $0.4<\mathrm{OES} \leq 0.5$ yaitu proses memotong intek menggunakan gunting, proses memotong kain keras tebal menggunakan gunting, proses menyesek kain keras tebal menggunakan pisau, proses merakit cup/upper dengan kain keras tebal dan proses mengoleskan lem ke tamsin menggunakan kuas sehingga status operasi menjadi 'diperlukan investigasi lebih lanjut, perubahan mungkin diperlukan' sedangkan sebanyak 17 proses memiliki nilai OES yang berada pada rentang $0.5<\mathrm{OES} \leq 0.7$ sehingga status operasi menjadi 'investigasi dan perubahan segera'.

\section{Simpulan dan Saran}

Perakitan sepatu dengan fasilitas kerja yang tersedia saat ini memaksa pekerja bekerja dengan sikap tubuh yang salah (awkward posture) dan sikap kerja tersebut dilakukan secara berulang selama durasi waktu kerja. Hal ini dibuktikan dengan hasil penilaian postur kerja, dimana dari 22 proses yang dilakukan terdapat 5 proses dengan nilai OES berada pada rentang $0.4<\mathrm{OES} \leq 0.5$ sehingga status operasinya 'diperlukan investigasi lebih lanjut, perubahan 
mungkin diperlukan' sedangkan sebanyak 17 proses sisanya memiliki nilai OES yang berada pada rentang $0.5<\mathrm{OES} \leq 0.7$ sehingga status operasi untuk 17 proses ini menjadi 'investigasi dan perubahan segera'. Sebagai dampak dari postur kerja yang tidak aman yang dilakukan oleh pekerja stasiun perakitan, pekerja merasakan sakit pada bagian-bagian tubuh tertentu.

Perlu dilakukan perbaikan dengan mendesain atau mendesain ulang fasilitas kerja sehingga menurunkan resiko postur kerja. Perbaikan yang akan dilakukan didasarkan pada operasi dasar dengan nilai PES tertinggi dengan pengulangan paling banyak agar tercapai tujuan menurunkan resiko postur kerja pekerja secara lebih efektif. Desain fasilitas kerja yang mungkin dilakukan untuk mengurangi level kekritisan adalah rak sulas yang didesain sedemikian rupa untuk mengakomodasi sejumlah sulas yang dibutuhkan selama perakitan di stasiun perakitan.

\section{Ucapan Terima Kasih}

Terima kasih peneliti sampaikan pada home industry Yessy Shoes baik pemilik maupun pegawai yang telah memberikan kesempatan untuk dijadikan tempat penelitian.

\section{Daftar Pustaka}

Adiputra, N. (2006). Experience on Application of Health and Safety Programme at A Company. Presented at the National Seminar Ergonomics-Safety and Health.

Budiman, E., dan Setyaningrum R. (2012). Perbandingan Metode-Metode Biomekanika Untuk Menganalisis Postur Pada Aktivitas Manual Handling (MMH). Sekolah Tinggi Wiworotomo, Purwokerto.

Bridger, R.S. (1995). Introduction to Ergonomics. McGraw- Hill Inc.,Singapore.

Cecchini, M., Colantoni, A., Massantini, R., Monarca, D., (2010). The Risk of Musculoskeletal Disorders for Workers Due to Repetitive Movements During Tomato Harvesting. Journal of Agricultural Safety and Health, Vol.16, pp. 87-98.

Dickinson C.E, Campion K, Foster A.F. (1992). Questionnaire Development: An Examination of The Nordic Musculoskeletal Questionnaire. Applied Ergonomics, Vol.23, pp. 197201.

Fagarasanu, M. and Kumar, S. (2002). Measurement Instrument and Data Collection: A Consideration of Constructs and Biases in Ergonomics Research. International Journal of Industrial Ergonomics, Vol. 30, pp. 251-265.

Hagberg, M., and I. Kuorinka. (1997). WMSDs: A Reference Book for Prevention. Taylor \& Francis, London.

Kuorinka, I., B. Jonsson, A. Kilbom, H. Vinterberg, F. Biering-Srensen, G. Andersson, K. Jørgensen. (1987). Standardised Nordic Questionnaires for The Analysis of Musculoskeletal Symptoms. Applied Ergonomics, Vol 18, pp. 233-237.

Savino, M., A. Mazza, D. Battini. (2016). New Easy to Use Postural Assessment Method Through Visual Management. International Journal of Industrial Ergonomics, Vol.53, pp. 48-58.

Tarwaka. (2004). Ergonomi Untuk Keselamatan, Kesehatan Kerja dan Produktivitas. UNIBA Press, Surakarta. 